\title{
An Approach for Flow Forecasting in Ungauged Catchments - A Case Study for Ho Ho reservoir catchment, Ngan Sau River, Central Vietnam
}

\author{
Dang Dinh Kha ${ }^{1 *}$, Nguyen Y Nhu', Tran Ngoc Anh ${ }^{1,2}$ \\ 1 Department of Hydrology and Water Resources, VNU University of Science, Vietnam National University, \\ Hanoi, 334 Nguyen Trai, Thanh Xuan, Hanoi, Vietnam \\ 2 Center For Environmental Fluid Dynamics, VNU University of Science, Vietnam National University, Hanoi, \\ 334 Nguyen Trai, Thanh Xuan, Hanoi, Vietnam \\ * Corresponding author's e-mail: dangdinhkha@hus.edu.vn
}

\begin{abstract}
Reservoir inflow forecasting with high reliability plays an important role in the operation and management of the reservoir for power generation, irrigation, flood prevention as well as ensuring the safety of the dam. However, the level of forecast accuracy is limited, since its performance depends on rainfall forecasting and hydrological model. In order to increase the efficiency of forecasting, this study introduces the inflow forecasting method that integrates the real-time updating techniques with continuous optimization method of MIKE NAM model to specify the appropriate parameter set for forecasting time. The proposed forecasting method was tested for the Ho Ho reservoir, the area facing the scarcity of historical data for model calibration and verification. The analysis of the forecasting results for Ho Ho reservoir using transferred parameters from the stable calibrated parameter values at Hoa Duyet station (downstream of Ho Ho reservoir) and the results obtained using the adapted parameters by the proposed method shows that the adapted parameter values provides a more reliable forecast, which will better serve the decision making.
\end{abstract}

Keywords: real time updating, flood, forecasting, ungauged catchment.

\section{INTRODUCTION}

Reservoir management can be viewed as an important strategic perspective for the socioeconomic development of a region, related to hydro-power development, water supply for irrigation, flood control etc. However, the variability of hydro-meteorological forcing and economic activities within the river basin are expected to significantly impact its characteristic. In order to maximize the performance of a single-reservoir as well as multi-reservoir system, having accurate reservoir inflow forecasting with enough lead time poses a challenge to water managers.

The development of model methods has been widely applied as an effective method for the reservoir inflow forecasting [An et al. 2012, Anh et al. 2015]. Coupled neural networks have recently become a well-known tool for better forecasting of the inflow hydrograph [Sanjeet et al. 2015, Krishna 2014]. However, in this model, a large amount of hydrologic data is required to determine the adaptive weights, which is usually unavailable in data-scarce regions. Using the distributed models may be inappropriate for real-time flow forecasting since the simulation can be time-consuming [Hapuarachchi et al. 2008]. A lumped model, therefore, is possibly the best choice for forecasting in an ungauged catchment. With the selected model, the accuracy of forecasting is prone to uncertainty depending on the forecasting meteorological data, forecasting scheme and the reliability of the used model. The aim of this study is to enhance the reliability of the model based on continuous optimization method to specify updated parameter values for reservoir inflow forecasting. For that purpose, model validation and calibration are key steps in any forecast models and simulation study. 
However, it should be noted that there is a limited number of river basins with long enough observed discharge data to capture the coverage of the hydrological event within the basin to both calibrate and validate the model, especially for the area with construction of new reservoir. Several studies "transfer" the parameter values of the model being specified for one catchment to the predicted catchment having similar characteristics [An et al. 2013, Bardossy 2007]. However, this procedure assumes that only one set of parameters is obtained, which possibly lead to a good model performance only for the events with similar conditions. In fact, due to the large complexity of the corresponding natural phenomena in Vietnam as result of its tropical monsoon climate and its time variation, the model parameters need to be transferred for the predicted catchment and the weather conditions under study. Further, the socio-economic activities within the basin have an influence on the hydrological regime coupled with the impact of climate change which leads to an increase in the complexity of hydrological processes in a catchment. Consequently, the identification of a unique dataset providing a good model performance for any weather conditions is practically impossible. In such a case, a flow forecasting system incorporating a real-time updating algorithm that adapts the model and catchment state can improve the forecasting accuracy. On that basis, this study tested and discussed the inflow forecasting method that integrates the real-time updating techniques including three categories: updating (1) input variables; (2) model parameters; and (3) output variables and the continuous optimization method of MIKE NAM model to specify parameters on the basis of reservoir water balance equation for the Ho Ho reservoir inflow forecasting.

\section{MATERIALS AND METHODS}

\section{Study area and dataset used}

The Ho Ho reservoir is constructed on the Ngan Sau River, a main tributary of La River located in Ha Tinh province, central Viet Nam. The area of Ho Ho reservoir catchment is 278.6 $\mathrm{km}^{2}$ with the storage capacity of the reservoir being 38 million $\mathrm{m}^{3}$. The Ho Ho reservoir officially operates from the beginning of 2013.

From 2017, three automatic rain gauges and an automatic water level recorder were installed upstream of the Ho Ho reservoir, these recorded data can be automatically updated for the database of reservoir management office.

In addition, the observed daily rainfall for 7 years from Jan 01, 2010 to Dec 31, 2016 were collected from the National Hydro-Meteorological Service, Vietnam for three stations Chu

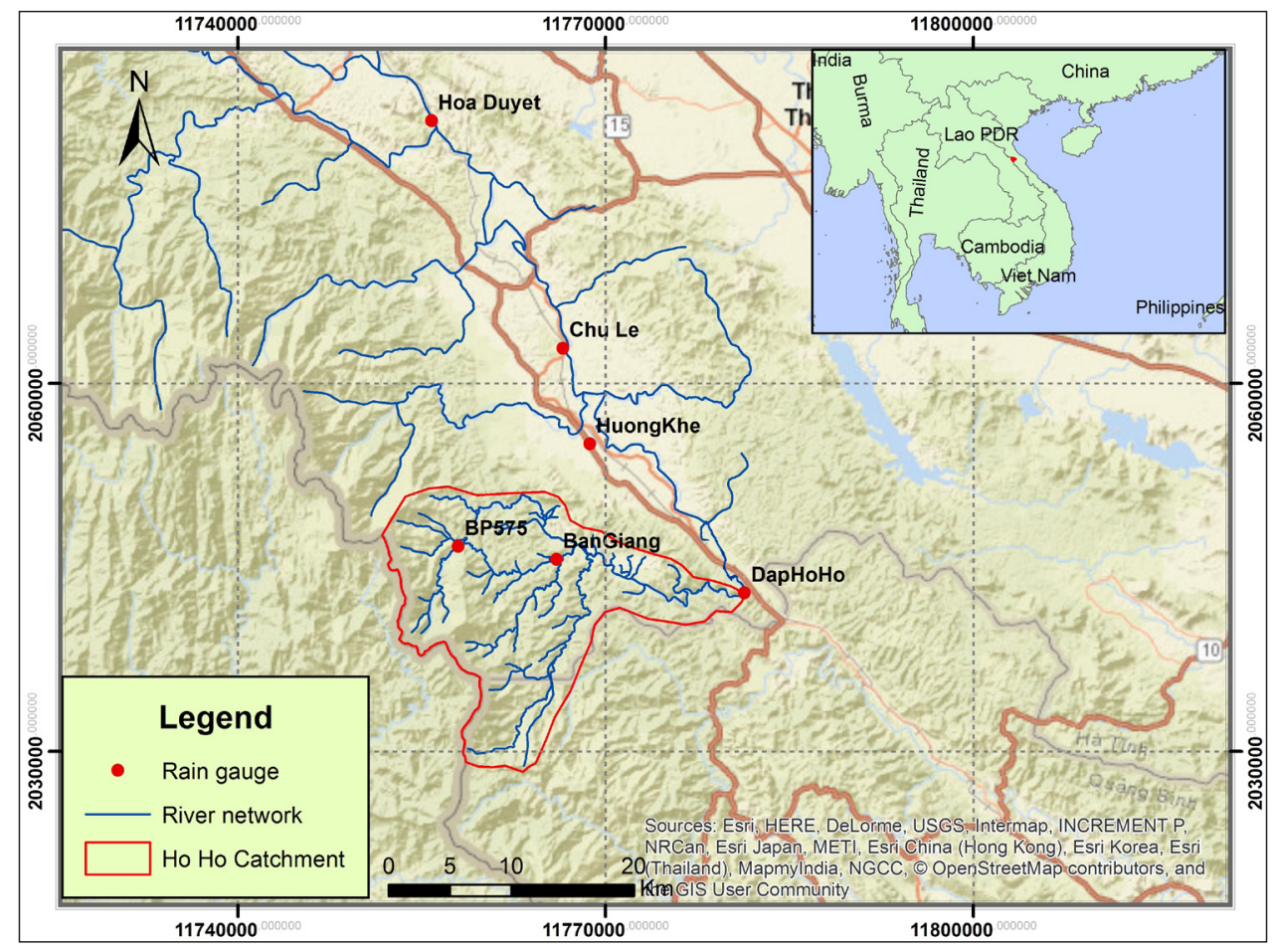

Figure 1. Rain gauge network in the study area 
Le, Huong Khe and Hoa Duyet in the study area (Figure 1). The daily water level and discharge with the same period were collected from Hoa Duyet station with the catchment area of 1880 $\mathrm{km}^{2}$, located downstream of the Ho Ho reservoir (71 km from the site). These data are employed for calibration and validation of the model to serve the reservoir inflow forecasting.

\section{Methodology}

MIKE NAM, a lumped model, developed at DHI Water \& Environment has been widely used in researches [Keskin et al. 2007, Liu et al. 2007, Kamel et al. 2008]. The model simulates the water movement in the land phase of the hydrological cycle by continuously accounting for the water content in four different and mutually interrelated storages, including snow storage, surface storage, lower or root zone storage and groundwater storage [DHI 2004]. The parameters of MIKE NAM model can be identified by either the manual trialand-error method or automatic optimization method. The auto-calibration is done to optimize two objective functions: (a) minimizing the water balance error (\%WBL) (b) minimizing the root mean square error (RMSE) [DHI 2004]. The auto-calibrated method provides the good performance in simulating each hydrological event, but with various hydrological events, they require different parameter sets to obtain good performance [Giang et al. 2010]. In recent years, MIKE NAM model has been considered as an efficient tool for forecasting and water resources assessment in Vietnam [An et al. 2013, Long et al. 2010, Giang et al. 2010]. However, most of the study focused on simulating the historical events with a single parameter set. In this paper, a different approach of integrating the real-time updating technique with optimization algorithm SCE (Shuffled Complex Evolution) with the RMSE objective function in MIKE NAM for parameter auto-calibration is applied. The calibrated parameters will be linked and updated automatically into the runoff model to forecast the inflow for the next time step. The rainfall and water level data from automatic recorder will be updated as input variables for parameters updating. The automatic water level recorders at the reservoir are used to estimate the reservoir inflow according to the reservoir water balance equation (1):

$$
\frac{d V}{d t}=Q(t)-q_{r}(t)
$$

where: $Q(t)$ - reservoir inflow $\left[\mathrm{m}^{3} / \mathrm{s}\right]$,
$q_{r}(t)-$ reservoir outflow $\left[\mathrm{m}^{3} / \mathrm{s}\right]$,
$d V / d t$ - varying of storage capacity of the reservoir in time $\left[\mathrm{m}^{3} / \mathrm{s}\right]$.

Simplified, the trial-and-error method will be used to solve the equation (1) which is based on the characteristics of reservoir, including water level - storage capacity relationships $\mathrm{Z} \sim \mathrm{V}$, water level - structure outflow (turbine, spillway) $Z \sim$ q, and water level - surface area $Z \sim F$. These relationships were developed based on the reservoir survey data.

The daily rainfall data collected from three stations Chu Le, Huong Khe and Hoa Duyet in the study area will be used to estimate the basin average rainfall with the Thiessen Polygon method. The model calibration and validation will be done by combining the trial-and-error with automatic optimization method to obtain the best result. The accuracy of simulation assessed by using the Nash-Sutcliffe coefficient, which were of 0.7 and 0.76 being obtained with the period of 2010-2013 and 2014-2016, respectively, for calibration and verification (Figure 2). This indicates that the obtained parameters were reasonably good for forecasting purpose at Hoa Duyet station.

In order to forecast the Ho Ho reservoir inflow, these parameters need to be transferred from Hoa Duyet to Ho Ho using regression relationships between the catchment area defined by Ho Ho reservoir $\left(278.6 \mathrm{~km}^{2}\right)$ and the one by Hoa Duyet station $\left(1880 \mathrm{~km}^{2}\right)$, referred to as parameter set 1 . The parameters of time constant for routing overland flow $(\mathrm{CK} 1,2)$ and baseflow $(\mathrm{BF})$ will be revised since they present high sensitivity to the catchment size.

Besides, the study integrates the real-time water level, rainfall updating algorithm and autocalibrated method in MIKE NAM to optimize the parameter values. The algorithm was developed in the Matlab environment to auto-update the observed data from recorder, auto-calibrate and forecast the Ho Ho reservoir inflow via MIKE NAM model. In turn, when the water level and rainfall at the reservoir are updated at time $t$, the model will auto-forecast the reservoir inflow at $t+\Delta t$, the parameters of MIKE NAM model at subsequent time step, $(t+2 \Delta t)$, can be obtained according to updating measured flow, water level and rainfall data at $t+\Delta t$. The updating observed input variables at $t+\Delta t$ and the re-update parameters for time $t+2 \Delta t$ (parameter set 2) will be used to forecast the inflow at $t+2 \Delta t$. It means that the parameter set 2 will be updated continuously to correctly reflect the catchment attributes at the predicted time. 


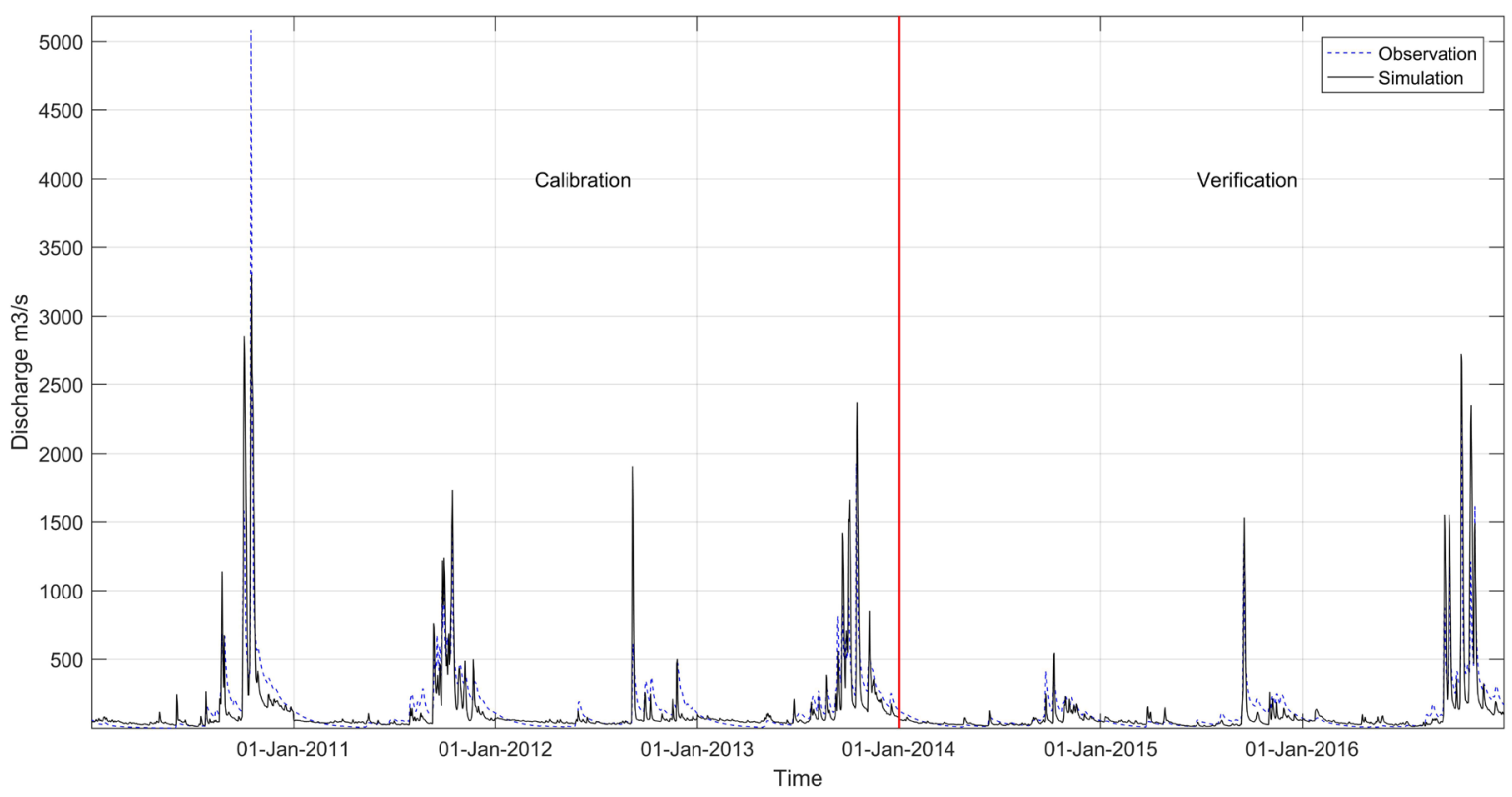

Figure 2. The observed and simulated discharge at Hoa Duyet station

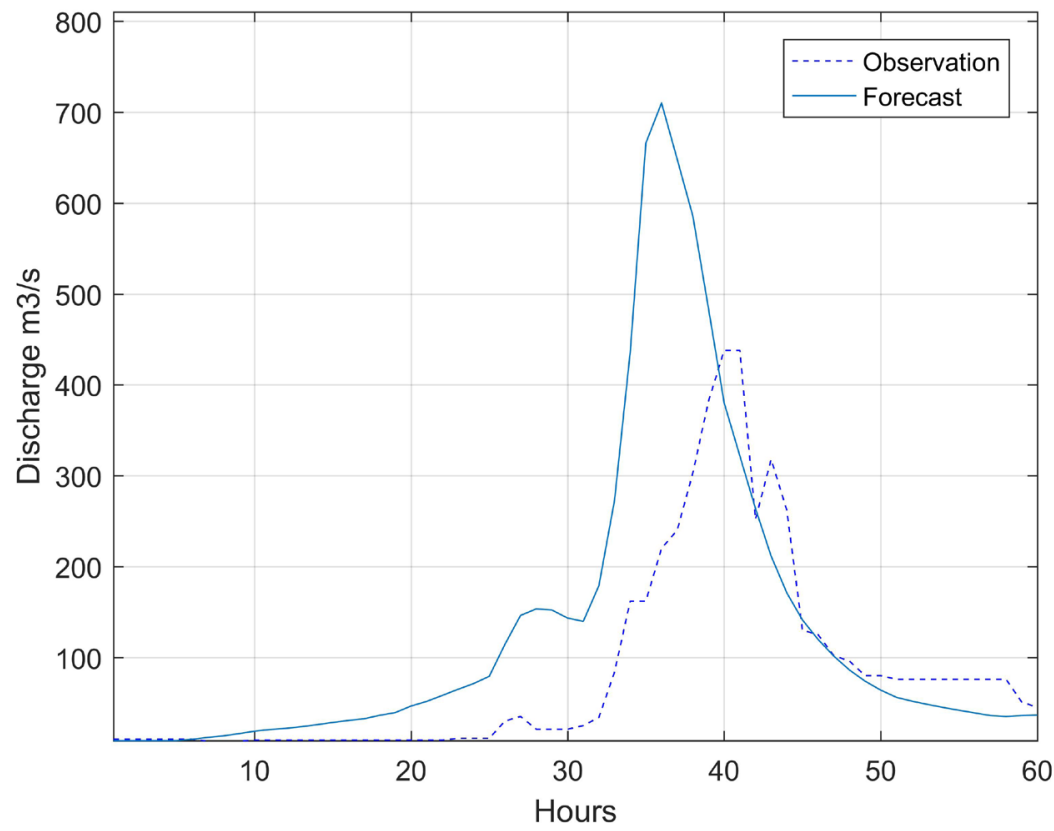

Figure 3. The observed and forecast discharge using the parameter set 1

\section{RESULTS AND DISCUSSIONS}

The hourly rainfall data of flood event from July 15, 2017 to July 17, 2017 were collected for forecast testing and the results are presented in Figures 3 and 4.

The Figure 3 indicates the forecasting result using the parameter set 1 ; it can be seen that under no rain conditions, water is kept in soil and water bodies on catchment to maintain the river, the model shows a good performance. However, under heavy-rainfall conditions, the result sug- gests that the model overestimated the simulated discharge, the error of flood peak flows was around $80 \%$. This indicates that reasonably good model parameters obtained during the calibration and validation at Hoa Duyet station, are not comparable for the forecast of the Ho Ho reservoir inflow. This is possibly because the parameter set 1 does not correctly reflect the attributes of catchment at the predicted time (soil humidity, land's water storage capacity etc).

The Figure 4 shows the observed and forecast discharge using the parameter set 2 for different 

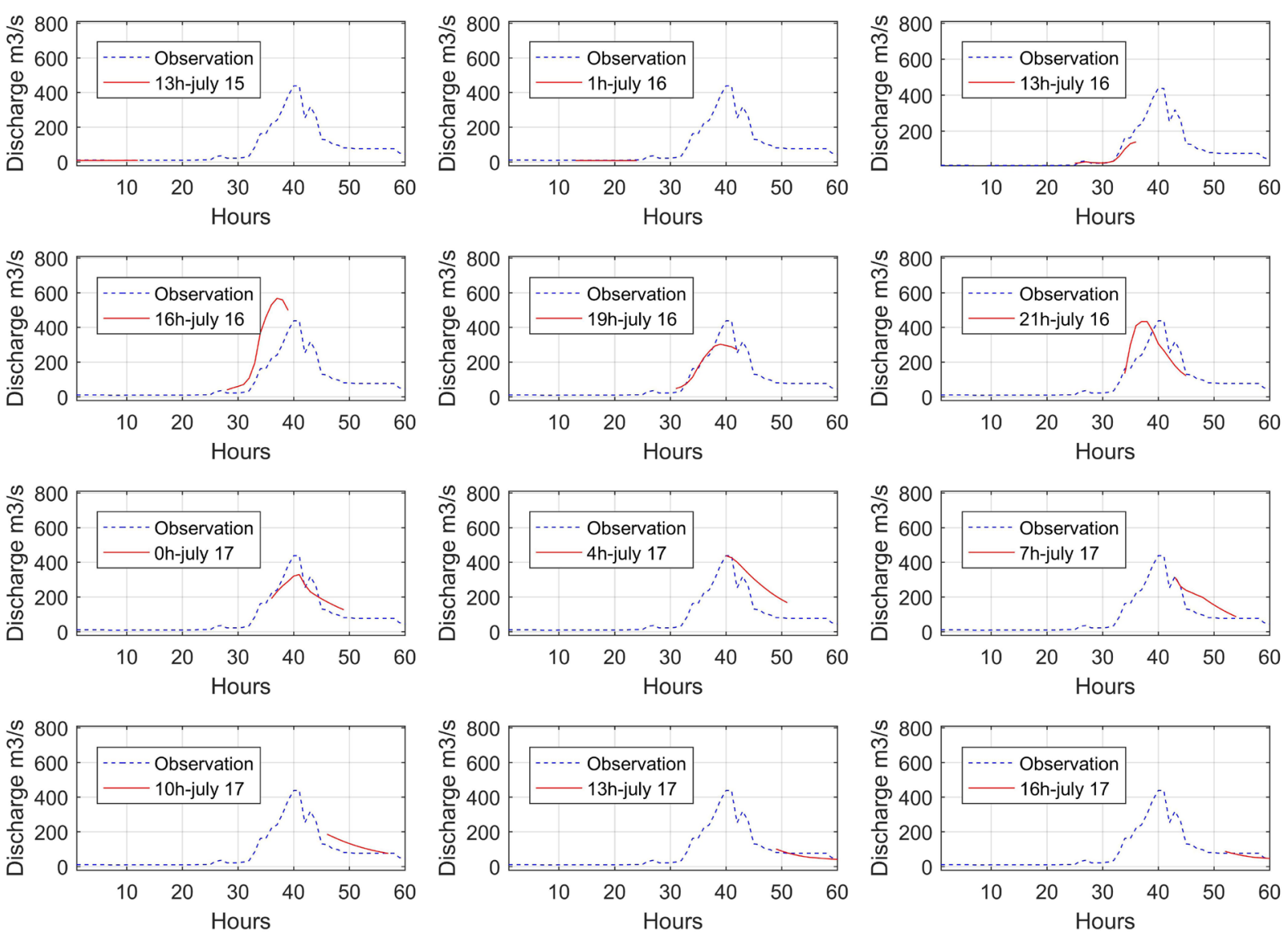

Figure 4. The observed and forecast discharged hydrograph using the parameter set 2

time steps. Similarly, under no rain conditions (from July 15, 2017 at 1:00:00 PM to July 16, 2017 at 1:00:00 PM) the model shows good performance as a result of stable inflow. At the initial time $t$ when rain occurs (July 16, 2017 at 4:00:00 PM) the model performed relatively worse with the forecast error of $45 \%$ for the 12 hours ahead forecast cases. The possible reason of this result is to employ the parameters optimized from the previous time step (the no rain parameter set) for the forecast cases. In order to make prediction at $t+1$ (July 16, 2017 at 7:00:00 PM), the model is updated with observed water level at $t$ of the Ho Ho reservoir which means that this optimized parameters somehow better reflect the attributes of catchment. As a result, forecast values are improved significantly; the errors are $10 \%$ and $20 \%$ with the lead time of 6 hours and 12 hours, respectively. The error of peak discharge for a 3 -h prediction is around $20 \%$. For the subsequent time steps $(t+2, t+3, \ldots)$ the forecast discharge hydrograph approaches ever closer to the observed discharge hydrograph. Even though the accuracy of inflow forecasting decreases when the lead time is increased because the forecast error is accumulated from the previous lead-time forecasting; these results indicate that the proposed inflow forecasting method can increase the credibility of forecast information in comparison with the forecast information using the transferred parameter values from another catchment.

\section{CONCLUSION}

Accurate and reliable forecasting of reservoir inflow highly depends on the meteorological forecasting (rainfall, temperature, etc.). As a result of using observed rainfall data, it somehow reduces the kind of error caused by input data.

The analysis was carried out with (1) the parameters transferred from the neighbour catchment, and (2) the parameters auto-optimized continuously based on the SCE algorithm and realtime updating at predicted time indicated that the latter method provides more reliable results than the former one. It is possibly because the autocalibrated parameters based on real-time updating algorithm have a good reflection of the catchment states at predicted time - a region having 
completely no data of catchment attributes (land humidity, land's water storage capacity, etc.), the forecast shows good agreement with the observed flow. Using the proposed method for the inflow simulation is advantageous, because it can provide credible forecast for the catchment without any historical discharge data. Nevertheless, the model parameters are capable of continually updating so that the forecasting at subsequent time steps can be operated with high accuracy; hence, the water level of the reservoir and observed rainfall need to be updated continuously. This raising point can be done by the installation of automatic gauges. For the 6-h, 12-h ahead forecast cases, the forecast error is $10 \%$ and $20 \%$, respectively. Although the accuracy of the forecast rainfall decreases as the lead time increased, the results indicated that a real-time updating algorithm incorporated into optimized auto-calibration method of the parameters of MIKE NAM model can enhance the efficiency of inflow forecasting for a data scarce region. Further research for more accurate and efficient prediction is still required. However, integrating the data assimilation algorithm into the forecast process to bridge the gap between the theory and practice can be a possible solution.

\section{Acknowledgements}

This research is funded by the VNU University of Science under project number TN.17.16.

The author is $\mathrm{PhD} /$ Doctoral Student under the 911 Program of VNU University of Science, Vietnam National University.

\section{REFERENCES}

1. An N.L., Ngoc N.T.B. 2012. Research on flood forecasting for reservoir in the Ba river. Journal of Water Resources \& Environmental Engineering, No 38 (in Vietnamese).

2. An N.L., Hoa N.N. 2013. Research on flood forecasting in Vu Gia - Thu Bon River Basin. Journal of Water Resources \& Environmental Engineering, No 43 (in Vietnamese).
3. Anh L.T., Son N.T. 2015. Some experiences for applying Hydrological, Hydraulic models to Hydrologic Forecasting, Journal of Science VNU. Natural Sciences and Technology, 31(1S) (in Vietnamese)

4. Bardossy A. 2007. Calibration of hydrological model parameters for ungagged catchments. Hydrol. Earth Syst, Scie., 11, 703-710.

5. DHI Water \& Environment. 2004. MIKE 11 Reference Manual.

6. Giang N.T. Phuong T.A. 2010. Calibration and verification of a hydrological model using event data, VNU Journal of Science, Earth Science, 26. (in Vietnamese).

7. Hapuarachchi H.A.P., Wang Q.J.A. 2008. Review of Methods and Systems Available for Flash Flood Forecasting; Report for the Bureau of Meteorology, Australia; Commonwealth Scientific and Industrial Research Organization (CSIRO): Dickson, Australia.

8. Kamel A.H. 2008. Application of a hydrodynamic MIKE 11 model for the Euphrates River in Iraq. Slovak Journal of Civil Engineering, 2, 1-7.

9. Keskin F., Sensoy A.A., Sorman A. 2007. Application of MIKE11 Model for the Simulation of Snowmelt Runoff in Yuvacik Dam Basin, Turkey. International Congress on River Basin Management, The role of general directorate of state Hydraulic works (DSI) in development of water resources of Turkey.

10. Krishna B. 2014. Comparison of wavelet based ANN and regression models for reservoir inflow forecasting. J Hydrol Eng, 19(7), 1385-1400.

11. Liu H.L., Chen X., Bao A.M., Ling Wang. 2007. Investigation of groundwater response to overland flow and topography using a coupled MIKE SHE/ MIKE 11 modeling system for an arid watershed. Journal of Hydrology, 347, 448-459.

12. Long V.D., Anh T.N., Binh H.T., Kha D.D. 2010. An introduction to flood forecast technology in Ben Hai and Thach Han river systems using MIKE 11 model. Vietnam National University Journal of Science, 26(3S), 397-404.

13. Sanjeet K., Mukesh K.T., Chandranath C., Ashok M. 2015. Reservoir Inflow Forecasting Using Ensemble Models Based on Neural Networks, Wavelet Analysis and Bootstrap Method. Water Resour Manage, 29, 4863-4883, doi: 10.1007/s11269015-1095-7. 